\title{
Geographical information system "The Earth's natural disasters Database" (ENDDB) as a tool for studying complex geotectonic structures*
}

\author{
A.V. Mikheeva, An.G. Marchuk
}

\begin{abstract}
The software of geographical information system for studying the Earth's natural disasters (GIS-ENDDB), focused on the research into the causeand-effect relations of catastrophic events in the history of our planet, contains data on seismic activity of the Earth, heat flows, detailed relief, and anomalies of the gravitational field as well as on the distribution of cosmogenic structures. The methods of analyzing these data are constantly being developed. All the above-said is necessary for the formulation and solution of many new geotectonic and geomorphological problems. For example, to confirm diagnostic morphological features of astroblems based on the facts (according to "Earth's impact structures Catalog"); to reveal patterns of seismogenic structures (according to seismological catalogs); to detect and to confirm structures of complex multistage Genesis such as the impactmagnetic, impact-tectonic (according to the entire range of data). Among the latest updates into the subsystems of information and mathematical software, there are functions of visualization of geophysical fields, the 3D visualization of the seismicity characteristics, and, also, the text and graphic data of geological and geophysical observations (tectonomagnetic, petrological, etc.) designed for a seismic prototype GIS-EEDB (the Expert Earthquake Database).
\end{abstract}

Keywords: Impact structures catalog, morphostructural elements, geophysical anomalies, impact-magnetic genesis.

\section{Geoinformation technology used in the ENDDB system}

The program GIS-ENDDB [1-3] is the result of combining geographical information systems for the analysis of the Impact catalog data [4-6] and seismological data, contained by now in more than 60 earthquake cata$\operatorname{logs}[1,7,8]$. The resulting system allows users (non-programmers) communicating with a computer to formulate and solve their own intellectual tasks. The methodological basis of the research is the methods of physicalmathematical analysis, the GIS-methods (mapping, development of geographical information systems, geo-information modeling, etc.), different approaches to the interpretation of the data.

\footnotetext{
*Supported by the RFBR under Grant 17-05-00003 .
} 

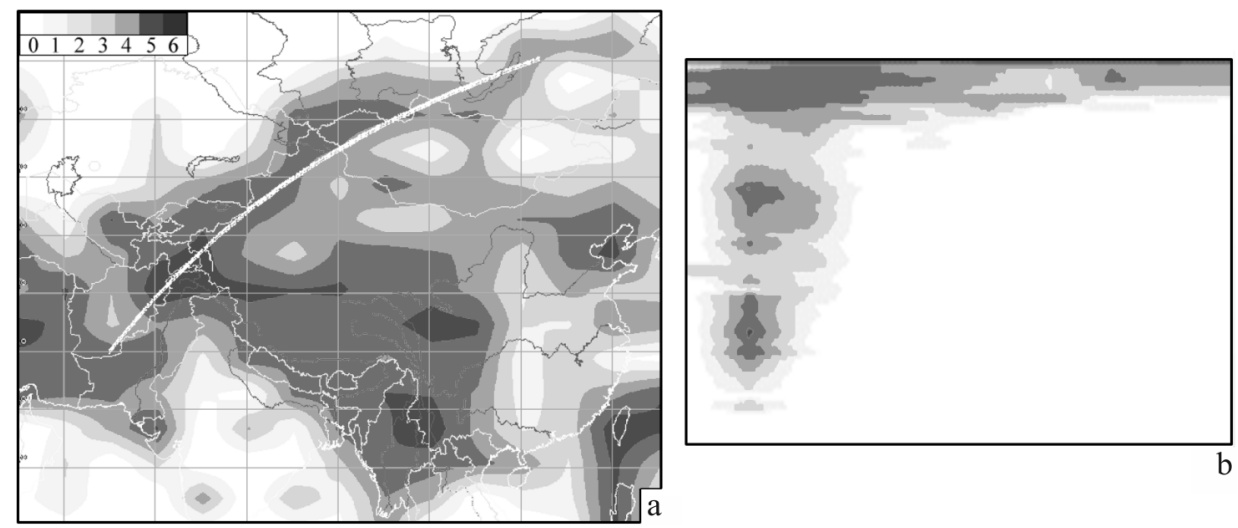

Figure 1. The isolines of total seismic energy according to COMPLEX catalog, $4 \leq M_{S} \leq 8$ : a) per unit area (the averaging cell is $3 \times 5^{\circ}$, the color zones $1,2, \ldots, 6$ correspond to the upper value of $E=45 \cdot 10^{4}, 47 \cdot 10^{5}, 49 \cdot 10^{6}, 52 \cdot 10^{7}, 54 \cdot 10^{8}, 57 \cdot 10^{9}$ Joules $/$ year $/ \mathrm{km}^{2}$ ); b) in the vertical section along the lineament profile (white arc in Figure 1a): $H_{\max }=300 \mathrm{~km}$

The methods of physical-mathematical analysis are the main principles of the theory of probability and mathematical statistics, the physical laws of the destruction of environment continuity, other achievements of Russian and foreign authors in the research subject area [9,10], etc. Methods of graphical and spatial-temporal analysis of the main characteristics of seismic and geodynamic processes $[7,8]$ inherited from the analysis subsystem of GIS-EEDB and supplemented by the functions of calculating their distribution in the cross-sections along the multi-directional profiles designated by the user thus allowing to obtain the multi-dimensional data visualization (Figure 1).

In addition, in the GIS-ENDDB environment the algorithms of detecting the events groups of the spatial and spatial-temporal range: aftershocks, swarms, scattering ellipses, clusters, chains, lineaments are being developed $[8,11-13]$.

All these updates help to extend the classical methods of geotectonic studies by a complex scientific-experimental approach allowing one to select tectonically active borders and faults, to study the spatial relationship of seismicity and cosmogenic paleo-structures (related to the historical past of the Earth) and, eventually, to interpret the data in terms of constructing seismic-geodynamic models of the lithosphere. For example, a comparison of results of formalized calculation lineaments with maps of real geophysical manifestations allow the identification of objective characteristics of seismic and geodynamic processes (in particular, the earthquake preparation), and in a larger scale - to put forward models of the global development of tectonogenic processes. That is to say, along with applications to solve 
fundamental problems of geodynamics, enriching our knowledge about the structure and dynamics of the geological-geophysical environment, reflected in the digital topographic and geophysical models, as well as in geological data. The latter are the geographical and geological-geophysical filling in the GIS-ENDDB system, which is also constantly developing.

For example, the algorithmic extension of ENDDB for conversion (transformation) of the original model of the gravitational field $[2,3]$ has been recently added in order to diminish the topography influence, as well as to identify the regional component of the gravitational field, which may reflect the mantle heterogeneities (according to [14]), and determine the basic underlying tectonogenic structures.

To divide the field into the regional and local components, the variations method or the Andreev-Griffin approach using the circular smoothing is used:

$$
\delta U(0)=U(0)-\Delta U(R),
$$

where $\Delta U(R)$ is the average value of a field $U$ on a circle of radius $\mathrm{R}$ specified by the user. The point with zero coordinates $U(0)$ is the value of the field in the middle of a sliding window. The average value $\Delta U(R)$ reflects regional anomalies, and its subtraction from the observed values at the center of the circle results in a local anomaly.

To construct the shadow (with side illumination) geo-model of a heat flow (HF) into the GIS-ENDDB, the HF measurements of the North Dakota State University [15] available in open access were incorporated. We translated these measurements into a regular grid using the Global Mapper tools, forming a digital model based on the linear interpolation. To this field the transformation function of the original field conversion can be also applied. In the case of the thermal field, this procedure allows us to smooth out local inhomogeneities caused by radioactive inclusions and some other factors of the local heterogeneity of rocks.

Methods of diagnosis of tectonic structures by the GIS-ENDDB means are in selecting an optimum foreshortening of an image, or parameters of the illumination ray and the shadow depth as well as in selecting optimal averaging values (if smoothing is necessary). This procedure allows us to obtain the most precise and informative three-dimensional images of a relief, gravity, heat flow and to gather data for establishing standard morphostructural elements of the ring and linear structures of cosmic and endogenous origin.

The lineament construction algorithm is also of great importance in our studies, with which earlier [13] we detected the central-oriented transform lineaments system of Central Asia (Figure 2c below) on the temporal interval of 2250 years. Using the GIS-ENDDB means, let us here consider the center of this system, which is a special geodynamic region called the Pamir Hindu 
Kush seismofocal (PHKS) zone.

\section{The Pamir Hindu Kush seismic zone}

First, at the point of cross-shape convergence of regional linear faults (Figure 2c), the multi-ring structure with diameter of $150 \mathrm{~km}$ to $300 \mathrm{~km}$ can be detected. This structure is independently detected according to the relief (including the satellite imagery ITRIS: http://labmpg.sscc.ru/impact/ a1396.html), as well as to the map of gravity anomalies (see Figures 2a and $2 \mathrm{~b}$ ). One may note the structural similarities of the multi-ring positive gravity anomaly above the PHKS zone with observations above the impact

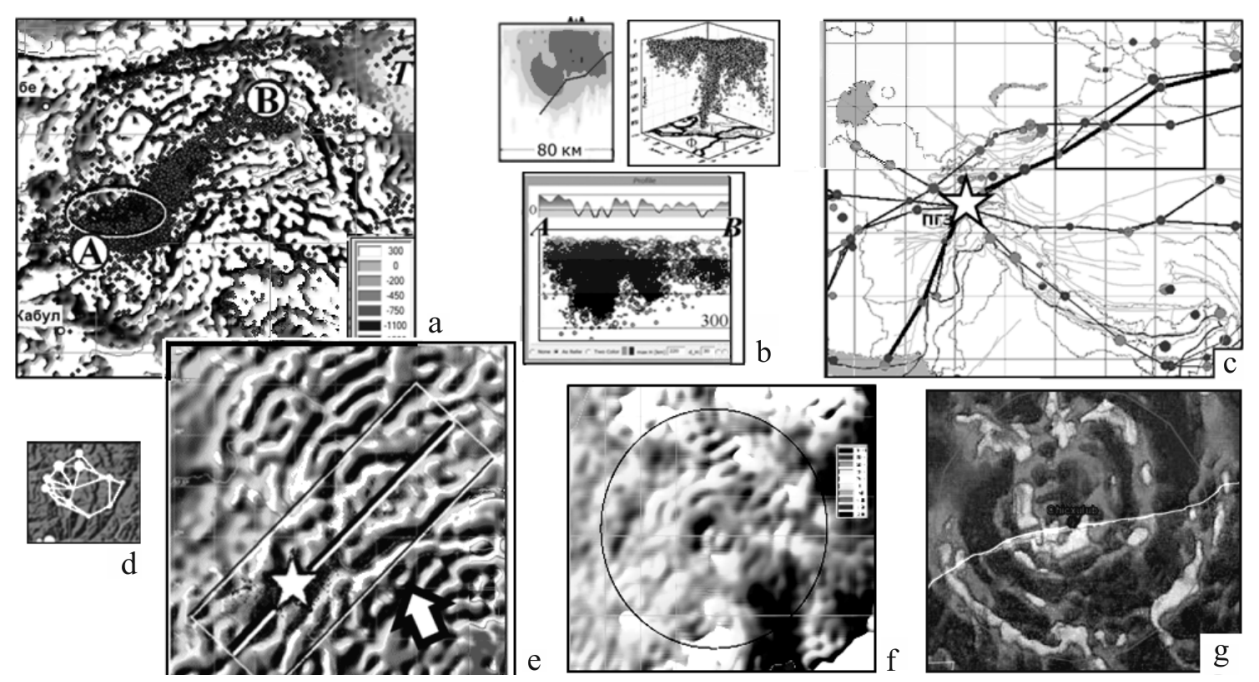

Figure 2. Structural elements of the PHKS zone and impact structures based on the gravity and seismic catalogs data (NEIC for 1973-2015 year and SIGN for -250-2008 year): a) deep seismicity with $H \geq 50 \mathrm{~km}$ (NEIC) on the background of a local component of the gravity anomaly in MGal (Andreev-Griffin transformation at $R=40 \mathrm{~km}$ ); b) a seismicity vertical cross-section along the $\mathrm{AB}$ profile from (a) (NEIC: $H \geq 40 \mathrm{~km}$ ); top: the $\lambda$-shape profile of the total seismic energy in the epicenter zone of Klyuchevskoy's volcanoes group (according to the GS RAS local catalog data: $H_{\max }=500 \mathrm{~km}$, the subduction boundary is identified according to NEIC: $M \geq 4$ ), and $\lambda$-shape seismic profile in the intersection area of the Philippines, the Okhotsk, the Pacific and the Eurasian plates (JMA: $H_{\max }=700 \mathrm{~km}$, up to 1990 [16], plate boundaries are indicated by thick lines); c) the lineaments system [13]; d) the deep circular lineament; e) a multi-ring gravity anomaly of the PHKS zone distorted by the collision (whose direction is indicated by the arrow). A white oval on (a) and asterisks on (c) and (e) mark the PHKS area of deep seismicity with $H \geq 200 \mathrm{~km}$. The maps of gravity anomalies above the proven impact structures: f) "Vredefort" ( $D=140-250 \mathrm{~km}, 2.023 \mathrm{Ma})$; g) "Chicxulub" $(D=180 \mathrm{~km}, 65.2 \mathrm{Ma})$ 
structures (for example, above the reliably established ones: "Vredefort" $D=140-250 \mathrm{~km}, 2.023 \mathrm{Ma}$; "Chicxulub" $D=180 \mathrm{~km}, 65.2 \mathrm{Ma}$; "Manicouagan" $D=100 \mathrm{~km}, 210 \mathrm{Ma}$ ) (see Figures $2 \mathrm{f}$ and $2 \mathrm{~g}$ ), but the shape of the above anomaly is more elongated and distorted by subsequent collisional processes (see Figure 2e). The center of this anomaly is slightly offset to the NE from the epicenter of deep seismicity cluster (see Figure 2e), where the deep circular lineament with $D \simeq 60 \mathrm{~km}$ (see Figure $2 \mathrm{~d}$ ) is revealed by the lineament construction procedure on a local scale.

It is known that the seismic focal PHKS zone is quite unique in the world deep narrow localized region in the continental conditions, where without apparent correspondence in the regional geological structure [17], more than 2000 earthquakes a year occur. A maximum earthquakes density is attained at depths of 200-250 km (see Figure 2d), in which ever recorded (since 958 according to the SIGN catalog), more than $60 \%$ of the PHKS zone strongest events $(M \geq 7)$ occur.

The nearly radial shape (see Figure 2c) of the junction of seismic lineaments in the PHKS zone (on the plan), and $\lambda$-shape configuration of the distribution of depth seismicity (in cross-section) (see Figure 2b) are similar to the pattern observed at the junction point of the four plates: the Philippine, the Pacific, the Okhotsk-sea and the Eurasian, where the so-called "seismic nail" $[16,18]$ exists (see Figure 2b, top, the right inset). Let us note that a similar $\lambda$-shape configuration of the depth distribution is observed in terms of weak seismicity and localized in the focal zone of Klyuchevskoy's volcanoes group (see Figure 2b, top, the left inset).

According to the GIS-ENDDB digital models of the heat flow, the increased anomalies in the thermal field (up to $276 \mathrm{~mW} / \mathrm{m}^{2}$ ) confined to the Pamir-Hindu Kush region are detected, which enhances the similarity of this zone to the above-mentioned junction of the four plates in the area of the West Pacific subduction, where there is an anomaly $(D \sim 200 \mathrm{~km})$ up to $475 \mathrm{~mW} / \mathrm{m}^{2}$. The comparison of HF map with the PHKS zone seismicity shows the coincidence of this anomaly with the top of the deep seismic swarm extending from this point to the west-south-westerly direction, moving deep along the profile $\mathrm{AB}$ at an angle of $\sim 25^{\circ}$ to the horizontal (see Figure 2b).

The spatial distribution of the mechanisms of deep seismic sources (with $H \geq 100 \mathrm{~km}$ ) shows (Figure 3) the preponderance of the upthrow mechanism in the PHKS zone, which sharply distinguishes the character of the movements of this zone from the area to the north-east (see Figure 3a). The predominance in the PHKS zone of the "seismotectonic deformations of near vertical uniaxial elongation" [18] suggests the presence in the area of a deep channel of material addition, which causes an active increase in the volume of rocks ("thrust"). At the same time, there is similarity in the types of earthquakes deformation of the PHKS focal depth with the sources 
of some modern eruptions of unknown nature (as, for example, Krafla and Bardarbunga in Iceland [17]).

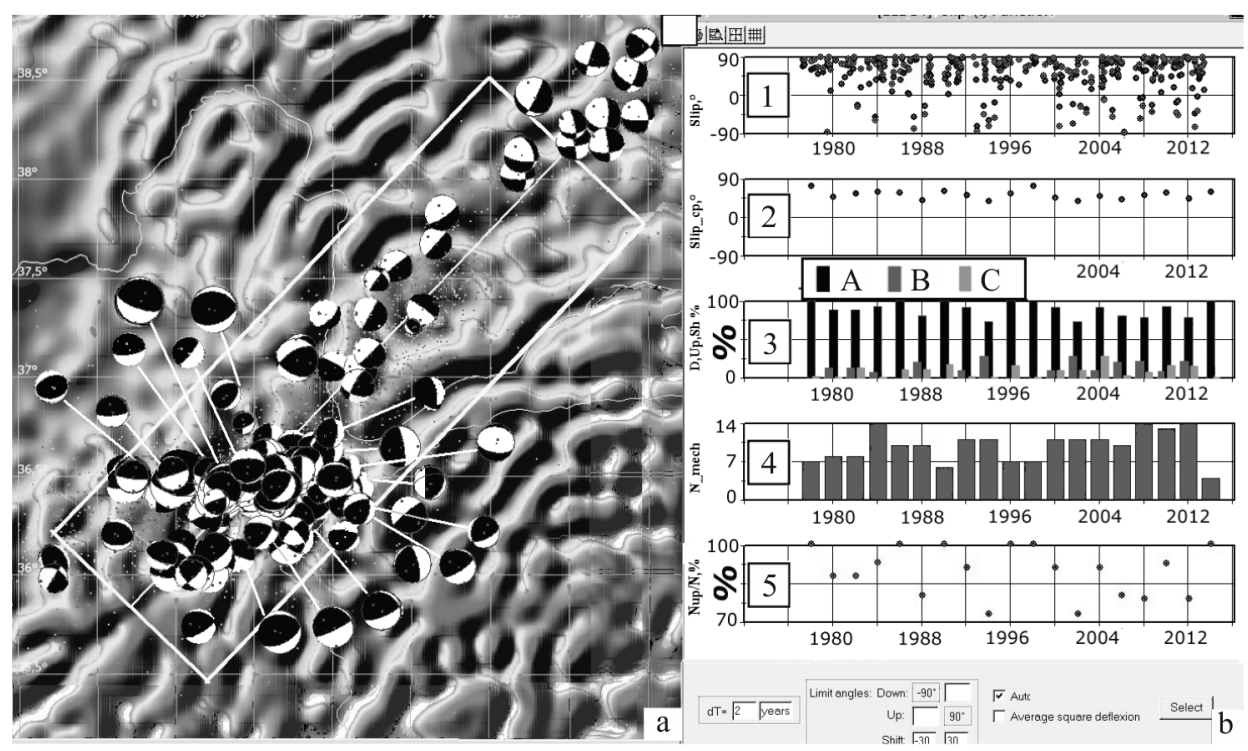

Figure 3. A distribution of the deep focal mechanisms $(H \geq 100 \mathrm{~km}$, NEIC catalog) in the Pamir Hindu Kush seismofocal zone: a) on a background of the gravity anomalies; b) the time distribution of the parameters: Slip, i.e. angle value between the fault plane stretch and the shift vector $(1-$ the whole Slips, 2 - the average one at the 2-year intervals); the relative amount (\%) of different mechanism types (3) (color A is the reverse faults, B is the discharges, $\mathrm{C}$ is the shifts), the mixed mechanisms are counted in both groups; the total number of mechanisms definitions (4), and the relative amount (\%) of the reverse type mechanisms (5)

Thus, despite the uniqueness of the PHKS zone, many of its characteristic features are found in other geodynamic areas: in the proven impactmagmatic structures, areas of volcanic activity, and even in subduction zones. This makes it possible to speak about a possible seismotectonic control of the activity of these areas by the deep mantle processes, i.e., by the activity of a possible deep mantle focus, calling "the accumulation in the upper mantle of the viscoelastic stresses and strains passed then to the seismogenic faults" [19]. In other words, we identified features (see, also, $[2,16,18]$ ) indicating to a tectonic control of regional seismicity, not only by the long-living deep faults but, also, by the focal depth source, i.e. by both linear and point deep structures.

Let us remind that earlier, a well-known Japanese seismologist Prof. K. Mogi [10] noted the determining role of deep seismic events in subduction zones: crustal earthquakes are preceded by an increase in deep seismic activity, and a strong shock occurs after the activation at a depth. Usually, when studying the effect of local mantle processes on the crustal seismic- 
ity and on the formation of circular relief shapes, the underlying causes of these processes are supposed to be a rise of the asthenosphere or a flow of fluids from the Earth's core, creating a vertical "tectonogens" (in terms of [20]). This mechanism of the formation is assumed to be endogenous both for "seismic nails" and for diatremes, volcanoes, dome-shape surface elevations, etc. These hypotheses are also confirmed for the Pamir Hindu Kush zone by analogy of its elements with the above listed structures. However, a number of questions still remains without explanation within the endogenous hypothesis: "what causes the tectonogens and determines their place; why are they often inclined but not vertical; why is there an energy concentration in a relatively narrow band? - There are no answers" [20]. It is also the presence of a centrally oriented system of regional scale faults in the crust difficult to explain. Meanwhile, there are hypotheses that give a clear physical model of the origin of such structures and directly pointing to energy sources for their formation. For example, in AA Barenbaum's model [21] the impact formation of deep sources of the majority of active intraplate structures is supposed, that is based on the physical phenomena of accumulation and "inelastic impact". The appeal of this model is not only in availability of numerous physical and theoretical bases [22,23], but also in the fact that not denying the endogenous mechanisms accepted in geology (magmatic diapirism, mantle plumes, hot-spots, etc. [24]), it supplements such mechanisms with a new energy component. The enormous kinetic energy of an intergalactic comet due to a hypersonic shock wave overcomes the rock strata of hundreds of kilometers, is passed to plutonic rocks, causing their heating and melting, i.e., there is created a deep focus of long-lasting tectonic and magmatic activity with a reserve of energy for millions of years.

Is the author's opinion, the data, obtained by means of the GIS-ENDDB, is best suited to this model. In this case, the super-regional lineaments of seismicity (see Figure 2c) associated with "seismic nails" can be interpreted as derivatives of the initial impact, generating the structure of a "broken plate" (in terms of "shock-explosive tectonics" [25]). This structure is activated by deep source processes, molten by the comet energy and by other geological processes, including the ones causing a relative movement of plates and agglomerates, which are described in the plate tectonics concept [26,27].

Let us note that in the geomorphological, geophysical, and mineralogical studies of recent years a number of authors have accumulated a considerable amount of material for classification of a number of ring structures of disputed origin as the category of complex multistage ring structures (impact-magmatic, impact-hydrothermal, impact-metamorphic, etc.) [25,28-33]. Moreover, in the catalog of impact structures of the Earth [4], for an overwhelming number $(83 \%)$ of the confirmed (plausible and probable) structures with $100 \leq D \leq 1000 \mathrm{~km}$, these or other geological manifestations 
of the volcanic and tectonic activity was marked.

Thus, the complex geomorphology of disputed geodynamic zones may also be associated with a complex multi-stage genesis, including various exogenous and endogenous geological processes. Summarizing the above arguments and continuing the analysis of data on the Pamir Hindu Kush seismic focal zone, we take into account the following:

- a possible depth of 100-350 km (reaching the asthenosphere) of a magma chamber formation due to the comet impact (according to the "galactic" hypothesis [34]),

- the circular nature of a positive gravity anomaly over the PHKS zone (see Figure 2e), belted by an area of submerged ring of $D \sim 300-$ $350 \mathrm{~km}$ (including the seismic-prone Tajik depression) (see Figure 2a), as was noted in the gravity of many proven impact structures (see Figures $2 \mathrm{f}$ and $2 \mathrm{~g}$ ),

- a tail-shape stretch of seismic activity cloud on the map (see Figure 2a) (along the deep Bartang-Pshatsk fault),

- an inclined stretch (with a depth increasing in the direction from NE to SW) of a seismicity cloud in vertical (see Figure 2b),

- the presence of a probable large astrobleme "Taklamakanskaya" ( $D=$ $300 \mathrm{~km}$ ) [4,25] (one of the largest deserts in the world) at the NE end of the seismicity cloud (marker $T$ in Figure 2a),

- the central-oriented "broken plate structure" detected by lineament constructions with the center in the PHKS zone (see Figure 2c),

- the presence of an intensive heat flow anomaly falling onto the beginning of the sloping Pamir Hindu Kush "tectonogen" [2].

Based on the above, we can assume the existence in this region of a track and subsurface response to the cometary impact action.

Let us note that the last comet showers of "medium intensity" as estimated in [21] could be about 5.0-0.7 million years ago, between Neogene and Quaternary. On the other hand, the recovery of orogenic movements of the intra-Asian mountain belt (including the PHKS zone and the Baikal rift zone areas) also refers to the latest time because everywhere within it, the remains of an ancient surface alignment are preserved being formed during the Late Cretaceous and Paleogene to the Late Eocene and Middle Oligocene [35].

The geodynamic data and maps [36] may indicate to a possible existence of a deep source of tectonic activity in the PHKS zone, showing the presence of a large active block of Early Precambrian basement (older than 1.6 Ma) along the whole deep seismicity tail, repeating in its configuration the PHKS 
zone [2]. This combination can testify the uplift of this area as a result of the deep volcano-tectonic activity through the centuries and material addition.

The analysis by means of the GIS-ENDDB tools of time distribution of parameters of focal mechanisms (see Figure $3 \mathrm{~b}$ ) shows a high prevalence of uplift shifts: from 70 to $100 \%$ of the total number of definitions for events deeper than $100 \mathrm{~km}$ (last graphic in Figure 3b). This can also speak about the phenomenon of "swelling" the solid surface of the planet, to which A.A. Barenbaum in his model refers as to a tectonic consequence of the galactic comet fall [23, p. 134].

The activation identified in the radial structures surrounding the Pamir Hindu Kush "seismic nail" (see Figure 2c) appears to be controlled by this source (also being complicated by the collision processes) and can have various activities at different time epochs.

\section{Conclusion}

The above example of using the GIS-ENDDB tools shows how wide and varied the range of the scales of geodynamic tasks, which this system can solve, as.

The comparative analysis of geodynamic features of different regions may be the key to understanding the causes of global geodynamic processes, such as not fully studied geodynamic phenomena of our time, for example, the seismic focal zone of the Pamir Hindu Kush. After comparing the data of studying this area $[15,26,27]$ with available information of the other regions, as well as with the "comet-galactic" hypothesis [21,23,34], its cosmogeneous nature was assumed. Assuming the impact formation of a radial fault system in the most "fragile" top layer of the Earth's crust as well as of the magma chamber in the mantle, leading to the post-impact tectonic activity, it is possible to agree on the whole aggregate of geo-information, geological and geophysical data for this area, supplementing the existing hypotheses of its formation.

Thus, due to the created tools, it is possible to simultaneously consider the data of geophysical observations, remote sensing, and catastrophic events catalogs for finding the new structural elements of different geological nature, for their comparison and comprehensive analysis.

Acknowledgements. The authors express their gratitude to Dr. P.G. Dyadkov for his participation in the further development of the seismological part of the GIS-ENDDB, as well as to Dr. I.I. Kalinnikov for the use and further development of the lineament construction algorithms. 


\section{References}

[1] Mikheeva A.V., Marchuk An.G., Dyadkov P.G. Geoinformation Systems for Studying Seismicity and Impact Cratering using Remote Sensing Data // Chapter 7 in Book: "Geographic Information Systems (GIS): Techniques, Applications and Technologies" / Nantes University, France.- Nova Science Publishers, 2014. - P. 151-216.

[2] Mikheeva A.V. Geostructural Elements Detected by Mathematical Algorithms and Numerical Models of the Geoinformation-Computer System GISENDDB.-- Novosibirsk: Omega Print, 2016 (In Russian).

[3] Mikheeva A.V. The new tasks of structural geomorphology, resolved by the ENDDB geoinformation system // Bull. Novosibirsk Comp. Center. Ser. Math. Model. in Geoph. - Novosibirsk, 2015. - Iss. 17.- P. 57-72.

[4] Mikheeva A.V. Web-site "The full catalog of the Earth's impact structures. 2461 records". - 2016. - http://labmpg.sscc.ru/Impact/ (application date: 01.04.2016).

[5] Alekseev A.S., Mikheeva A.V. The new data of "Catalogue of the Earth's impact structures" // Geochimica et Cosmochimica Acta. Suppl. 1. - S19, July 2008. - Vol. 72 (12).- P. A627-A627.

[6] Mikheeva A.V., Khazanovitch-Wulff K.K. Traces of the gravitational effects of large bolides // Geoinformatics. - 2014. - No. 1.-P. 30-41.

[7] Mikheeva A.V., Dyadkov P.G., Marchuk An.G. Geographic information system GIS-EEDB and methods of spatial-temporal analysis of seismological data // Geoinformatics. - 2013. - No. 2.-- P. 58-65 (In Russian).

[8] Dyadkov P.G., Mikheeva A.V. The EEDB - expert earthquake database for seismic-geodynamic research // Bull. Novosibirsk Comp. Center. Ser. Math. Model. in Geoph. - Novosibirsk, 2010.- Iss. 13. - P. 15-30.

[9] Gitis V.G., Ermakov B.V. Fundamentals of Spatial-Temporal Forecasting in Geoinformatics.-Moscow: FIZMATLIT, 2004 (In Russian).

[10] Mogi K. Relationship between shadow and deep seismicity in the western Pacific region // Tectonophysics. - 1973. - No. 17. - P. 1-22 (In Russian).

[11] Mikheeva, A.V. General Laws of spatial-temporal distribution of the Earth's impact structures // Bull. Novosibirsk Comp. Center. Ser. Math. Model. in Geoph.--Novosibirsk, 2010.-- Iss. 13.-- P. 127-140.

[12] Dyadkov P.G., Mikheeva A.V. Methods for detection of spatial clustering of earthquakes in seismogeodynamic study areas of Central Asia // Mathematical methods of pattern recognition: The 15th All-Russian Conference (Petrozavodsk, September 11-17, 2011): Proc. rep.--Moscow: MAKS Press, 2011.P. 560-563 (In Russian). 
[13] Kalinnikov I.I., Mikheeva A.V. The GIS-EEDB computing system, lineaments and a problem of earthquake prediction // Bull. Novosibirsk Comp. Center. Ser. Math. Model. in Geoph.--Novosibirsk, 2015.--Iss. 17.-P. 17-34.

[14] Ippolitov O.M., Nadezka L.I., Efremenko M.A. Some comments on the relation between the structural elements of the transformed gravity field and the spatial position of the earthquake epicenters in the VKM territory // Structure, properties, dynamics, and suggests of a lithosphere of the East European platform. Proc. 16th Int. Conf. Voronezh, 2010.-- Vol. 1. - P. 312-316 (In Russian).

[15] The global heat flow database of the international heat flow commission. Site Provided by the University of North Dakota, 2015. - http://www.heatflow. und.edu/index2.html.

[16] Vladkovsky V.N. Subvertical accumulation of earthquake hypocenters - seismic "nails" // Vestnik ONZ RAS. - 2012. - No. 4. - NZ1001 (In Russian).

[17] Shevchenko V.I., Dobrovolsky I.P., Lucc A.A. Deformation of uniaxial extension and focal mechanisms anomalous of earthquakes in the crust of the Tajik Depression // Geophysical Research. - 2010. - Vol. 11, No. 1. - P. 15-26.

[18] Shevchenko V.I., Arefjev S.S., Lukk A.A. Near-vertical clusters of earthquake sources not related to the tectonic structure of the Earth crust // Physics. 2011. - No. 4.- P. 16-38 (In Russian).

[19] Sarkar I., Sanyal S. Static stress transfers in the Pamir Hindu Kush seismic zone // J. Asian Earth Sci.-2004.--Vol. 23, No. 4.-P. 449-459.

[20] Nikolaev N.I. The Newest Tectonics and Geodynamics of the Lithosphere.Moscow: Nedra, 1988 (In Russian).

[21] Barenbaum A.A. A possible mechanism of the lithosphere rocks heated by galactic comets // Ural Geological J.-2013.-No. 1 (91).-- P. 21-39 (In Russian).

[22] Alekseev A.S., Petrenko V.E. Examples of numerical simulation of high-speed collision of solid bodies in the hydrodynamic approximation // Claim 5: Research reflective-radiative characteristics of space debris in various ranges. Developing formation models and the evolution of cosmic objects and synthetic particles in near-Earth space.- Novosibirsk, 1992.--(Report / USSR Academy of Sciences. Computing Center; Theme "Light-2", book 5) (In Russian).

[23] Barenbaum A.A. Galactocentric Paradigm in Geology and Astronomy. Moscow: LIBROKOM, 2010 (In Russian).

[24] Puchkov V.N. "The great debate" about the plume: so who is right after all? // Geotectonics. - 2009. - No. 1.-P. 3-22 (In Russian).

[25] Zeilik B.S. Shock-Explosive Tectonics and a Plate Tectonic Synopsis-AlmaAta: Gylym, 1991 (In Russian). 
[26] Pegler G., Das S. An enhanced image of the Pamir-Hindu Kush seismic zone from relocated earthquake hypocentres // Geophys. J. Int. - 1998. - Vol. 134, No. 2.- P. 573-595.

[27] Sippl C., et al. Geometry of the Pamir-Hindu Kush intermediate-depth earthquake zone from local seismic data // J. Geophys. Res. B.-2013.--Vol. 118, No. 4.-P. $1438-1457$.

[28] Zotkin I.T., Tsvetkov V.I. Search for meteorite craters on the Earth. // Solar System Research.-1970.- No. 1, Iss. 4.-P. 5-65 (In Russian).

[29] Malkov B.A. Ore otential major (Kara, Popigai, Kozhimskaya) and giant (Vredefort, Sudbury, Bangui) astroblems // Diamonds and Precious Metals of Timan-Ural Region. - Syktyvkar: Geoprint, 2006.- P. 25-26 (In Russian).

[30] Masaitis V.L., et al. Geology of Impact Craters. - Leningrad: Nedra, 1980 (In Russian).

[31] Dressler B. Shock metamorphic features and their zoning and orientation in the Precambrian rocks of the Manicouagan Structure, Quebec, Canada // Tectonophysics. Part 4.-1989. - Vol. 171, No. 1.-P.229-245.

[32] Officer C.B., Carter N.L. A review of the structure, petrology, and dynamic deformation characteristics of some enigmatic terrestrial structures // EarthSci. Rev. - 1991. - Vol. 30, No. 1.-P. 1-49.

[33] Pirajno F. Hydrothermal processes associated with meteorite impact structure: evidence from three Australian examples and implications for economic resources // Austral. J. Earth Sci.-2005.-Vol. 52, No. 5.-P. 587-605.

[34] Barenbaum A.A. Tectonomagmatic investigation of galactic comets falls on the terrestrial planets // Experimental Geochemistry. - 2014.- Vol. 2, No. 1.P. 20-26 (In Russian).

[35] Zonenshain L.P., Kuzmin M.I., Natapov L.M. Plate Tectonics in the USSR Territory: Vol. 2.-Moscow: Nedra, 1990. (In Russian).

[36] Rundquist D.V., et al. Web-site "Electronic Earth". - 2006. - http://earth. jscc.ru/index_en.php. 